\title{
Speedy sequencing technologies help track food-borne illness
}

The monumental Food Safety Modernization Act, signed into law by US President Barack Obama in January, promises to add muchneeded improvements to the security of the US food supply. Yet a technological advance, rather than a major legislative overhaul, could have the largest impact on the government's ability to identify contaminated foods and rid them from store shelves.

In a proof-of-principle study published last month, scientists from the US Food and Drug Administration (FDA) reported that, compared with traditional DNA fingerprinting, next-generation sequencing more precisely identified the bacterial strain and the food product responsible for a 2009-2010 outbreak of Salmonella that sickened more than 250 people across the US.

In response to that outbreak, a Rhode Island food manufacturer recalled nearly 1.5 million pounds of salami, prosciutto and other spiced deli meats. At the time, food safety officials couldn't tease apart which particular ingredient had made people sick, as standard genetic fingerprinting techniques alone proved inconclusive. But, in a retrospective analysis, FDA researchers used so-called shotgun sequencing to identify the cause of the outbreak: a particular strain of Salmonella contaminating pepper spices used to coat the deli meats (New Engl. J. Med. 364, 981-982, 2011).

Using new sequencing technologies to decipher food-related illness "may help pinpoint the source faster and implement recall procedures for all affected products-things that could definitely mitigate the severity of an outbreak," says Byron Brehm-Stecher, a food scientist at Iowa State University in Ames who was not involved in the study. Eric Brown, acting director of the FDA's microbiology division, acknowledges that next-generation sequencing techniques will be useful in the future, but he cautions that the current pace of data analysis precludes using these methods in the midst of rapid-response food safety emergencies.

Sequencing alone will also never fix all of the government's food tracking woes. As exemplified by another paper published last month, spotty record keeping in the food supply chain continues to hinder investigations of foodborne illness. In that study, scientists from the US Centers for Disease Control and Prevention argued that better product traceability could have prevented the mistaken identification of tomatoes in a major 2008 Salmonella outbreak. The contamination was later found to be linked to jalapeño and serrano peppers (New Engl. J. Med. 364, 918927, 2011).

To fill in the gaps, the FDA, backed by funding from the country's new legislation, is establishing a full-time, multidisciplinary team of about 40 people to handle outbreaks as they happen. And, to lead the group, the agency is currently recruiting a new medical director to serve as the 'point person' on decisions over food product recalls and facility inspections.

Such measures strengthen the FDA's ability to do science-based prevention of foodborne disease, argues Jeff Farrar, the agency's associate commissioner for food protection. "Obviously, if you are an entirely reactive agency it is very difficult to get ahead of the curve," he says.

Michelle Pflumm

\section{Drugs development is cheaper than widely claimed, experts say}

The sky-high costs of research and development are often cited by the pharmaceutical industry to justify the steep prices charged for prescription medicines. But the widely touted sticker price of bringing a new drug to market might be radically inflated, new research shows.

In a study published in February, two health policy experts argue that companies spend around $\$ 60$ million after discovery costs to test a new biologic or small-molecule drug - a far cry from the $\$ 1.3$ billion estimate normally bandied about by the drug industry. If confirmed, the markedly lower price of drug development could undermine big pharma's claims that generous tax breaks and high drug prices are needed to spur medical innovation.

"Economists over the last 35 years have found more and more ways to make the costs as high as possible, and that's been the chief lobbying tool for the industry," says study coauthor Donald Light, a health policy researcher at the University of Medicine and Dentistry of New Jersey in Stratford.

The often-cited $\$ 1.3$ billion figure traces its roots back to a 2003 report from a team led by Joe DiMasi, a health economist at Tufts University Center for Drug Development in Boston. In that study, DiMasi and his colleagues asked 24 drugmakers to submit their cost outlays to research and develop new medicines. The researchers considered 68 drugs from ten companies and found that the average out-of-pocket expense was around $\$ 400$ million. Factoring in the cost of research into failed drugs and the monetary hit incurred by not investing that money on the stock market during the time needed for preclinical research, trials and regulatory review, the authors concluded that $\$ 800$ million was typically needed to bring a drug to market ( $J$. Health Econ. 22, 151-185, 2003). Adjusting for inflation, in 2006 the Washington, DC-based Pharmaceutical Research and Manufacturers of America (PhRMA) then bumped the number up to $\$ 1.3$ billion.

According to Light, however, this figure is a gross overestimate for the drug industry as a whole. Together with economist Rebecca Warburton of the University of Victoria in British Columbia, he came up with a number around 20 times less than the prevailing billiondollar-plus metric. Notably, in their analysis the duo considered all new drugs approved by federal regulators-including licensed drugs and reformulations-rather than just the more expensive ones discovered in house (BioSocieties 6, 34-50, 2011).

Independent validation of the new cost estimate is still needed, notes Kevin Outterson, a drug pricing analyst at Boston University. But if it is proven correct, and drug development is as inexpensive as the new calculations suggest, then drugmakers have a lot of explaining to do. "If Light is right, then the industry should be producing more drugs," Outterson points out. Last year, US federal regulators approved only 21 new drugs, despite the industry reportedly spending more than $\$ 60$ billion on research and development.

DiMasi, for his part, stands by his original findings, describing Light's methodologies as "invalid." He argues that only his approach considers the total cost of drug development from initial discovery, and he points to independent validation from others: last year, for example, economists at the US Federal Trade Commission similarly pegged the cost of drug development at around \$1 billion (Health Econ. 19, 130-141, 2010). PhRMA declined to comment for this story.

Michelle Pflumm 